\title{
Intelligent Systems for Detection and Control Damage on Buried Infrastructure due to Soil Subsidence
}

\author{
Silvia García ${ }^{1 *}$ and Mauricio Jessurun ${ }^{2}$ \\ ${ }^{1}$ Professor-Researcher, Instituto de Ingeniería, UNAM, Mexico \\ ${ }^{2}$ President, Group UNISOL, Mexico
}

Submission: November 11, 2019; Published: January 22, 2020

*Corresponding author: Silvia García, Professor-Researcher, Instituto de Ingeniería, UNAM, Mexico

\begin{abstract}
Subsidence and its impact on infrastructure and urban systems is a serious problem for many of the most densely populated cities in the world and a huge challenge for those who develop safe, sustainable and resilient communities. In Mexico City, from the government's call to generate solutions to this problem, a huge multidisciplinary project is being developed to attack the most pressing fronts: control of the effects, management of the pumping of the aquifers, simulation of catastrophic scenarios for the reintegration of the inhabitants in sites with better capacities to hold communities. This presentation summarizes the contributions about digital twins of the soil/rock masses (key properties and their evolution) and the controlling system to prevent and to repair leaks in pipeline networks. Evaluate these aspects permits study future pumping scenarios to assist in selecting an optimal rate of extraction that minimizes overall subsidence, meet the requirements of city development plan and be consistent with continued sustainable economic development. No doubt about the many other aspects that need to be analyzed but this first stage is crucial to start a reconfiguration of the city life, reconciled with nature, aware of the ravages of excessive and unbalanced consumption of the vital liquid.
\end{abstract}

Keywords: Subsidence; Compressible clays; Cracking; Neural networks; Artificial intelligence; Digital twins; Intelligent water grids

\section{Introduction}

Over drafting of aquifers is the major cause of subsidence in megacities that uses groundwater as their main source of water supply. In many aquifers, ground water is pumped from pore spaces between grains of sand and gravel, when this aquifer has beds of clay or silt, the lowered water pressure causes slow drainage. For clays and silts, the reduced water pressure means a loss of support and because of the compressibility of these materials a lowering of the land surface is experienced $[1,2]$.

Land subsidence causes many problems including:

a) changes in elevation and slope of streams, canals, and drains;

b) damage to bridges, roads, railroads, storm drains, sanitary sewers, canals, and levees;

c) damage to private and public buildings; and

d) failure of well casings.

An example of damage caused by land subsidence exacerbated by the catastrophic September 19 192019 earthquake that hit
Mexico City can be seen in Figure 1. The road, drinking water pipes and sanitary sewers suffered sudden ruptures because the land surface lowered while the seismic waves passed through the soil deposit. At these points a sinking process had already been registered that alerted the inhabitants and forced the emergency teams to deal with constant leaks in the liquid conduction pipes but during the earthquake there was a decrease in the surface level (already deformed) of up to $1 \mathrm{~m}$ in less than a minute. The detrimental consequences on regional and local businesses, economies, and living conditions because of subsidence forces the operation of methodologies that try to forecast and control the manifestations of susceptible soils to this phenomenon. In the Mexican capital are being developed projects that exploit the advantages of artificial intelligence [3] and advanced sensing as an integrated system for the detection, early warning, and control of subsidence with special interest in managing the pipeline networks in selected areas of Mexico City. A method based on the geographic information system has been proposed to quickly and automatically optimize the layout of the instruments which detect sinking processes and leaks. 


\section{Civil Engineering Research Journal}

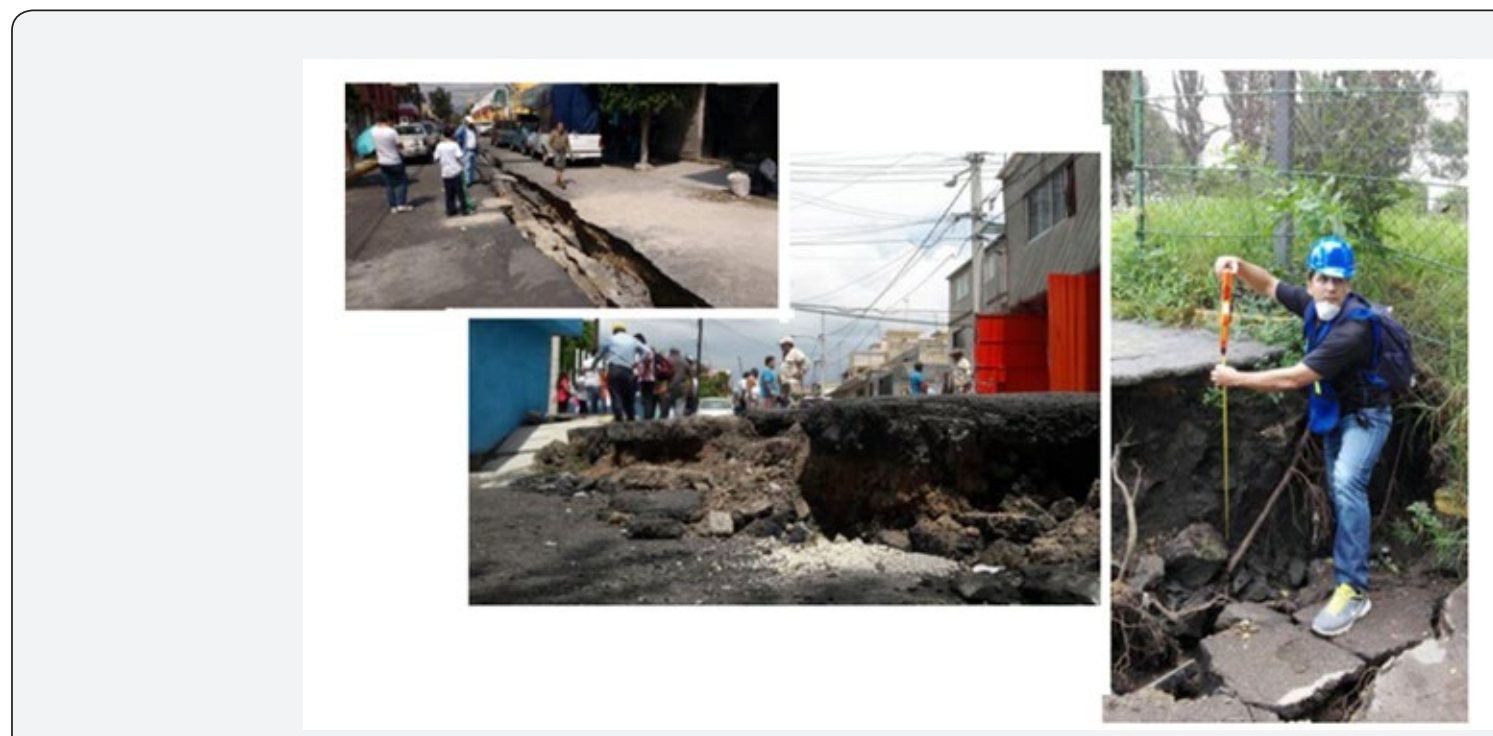

Figure 1: Effects of subsidence in the Transition Zone in Mexico City, sudden manifestations that occurred during the earthquake of the September $19^{\text {th }}, 2017$ (M7.1).

\section{Dynamical Modeling of Complex Soils Systems}

Soils and rocks systems are highly dynamic, with behaviors that vary on wide temporal and spatial scales. In addition, they are subject to water pumping in deep aquifers, urban development charges, and continuum transformations due to the developments of outsized buried civil works. Using the deep knowledge of the geotechnical situations in the metropolis, modular recurrent neural networks [4] have been implemented into a centralsoftware system that models the evolution of materials behavior. As inputs the system has the site-specific stratigraphy (a 4D object or digital twin of specific volumes), the groundwater conditions (a network of groundwater-level monitors) and the reports of a RPAS (Remotely Piloted Aircraft System) [5] of the position (on two orthogonal axes) of strategic points in areas with high vulnerability to sinking or cracking. Analyzing the outputs of the modular networks the user will be able to anticipate the performance of the soils under specific field conditions. The intelligent tool will allow analytically and computationally fully describe the complex dynamics and interdependency of soils and infrastructure systems.

\section{Intelligent Water Grids}

In order to achieve an efficient real-time system for leaks mitigation, the most extensive high-density ground motions/ flow conditions monitoring in Mexico City is being developed. The Emergency Water Supply Interruption System for Soils (patented technology) employs micromachining technology for measuring ground acceleration, detecting abnormal water flow conditions, and for fuzzy control of warnings. The system configuration is designed for high-precision estimations of damage and failures detection in real time. Dynamic neural networks are used for forecasting the surface distribution of ground motions and for constructing the premises and conclusions for alerts and cuttingoff of water supply. The system operation is very precise, simple, and highly reliable. The procedure intends to be a transition from the common "rigid" alarm systems to a more balanced and "flexible" approach, involving comprehensive measures (displacements, accelerations and flow conditions), real-time damage estimation (surface distribution of ground motions that takes into account soils site factors) and an "intelligent" environment for decisions about cutting-off of supply and dispatch of emergency teams to repair pipelines.

Intelligent water grids have the potential to revolutionize the interaction between hydrologic systems, and man-made infrastructure. Through advances in sensing, computation and control it is possible to couple the flow of water, with the flow of information, permitting modern water infrastructure to make automated decisions based on an intimate knowledge of its overall state. At a later stage, intelligent meshes will be used to control the pumping based on historical expenditure and deformation measurements. It is essential to add government wills to the efforts of researchers and analysts to compile a good database that allows to conclude on causes and effects. The adoption of advanced and advantageous technology, in the never-ending processes of figuring out what is happening below the surface, is possible now more than ever. Instruments, sensor networks, communication and data storage exist, is reachable and as time goes by, becomes more accessible in economic terms. But it is imperative that government and private institutions look at it as a virtuous investment and not only costly occurrence. However, it is important to mention that innovation means results like cost reduction on the government side or profits if the private sector 
oversees operating a water and sewerage system. If innovation does not mean economic related results, the set of activities be merely "good ideas".

\section{Concluding Remarks}

Technology is evolving at a breakaway pace making human life more convenient by raising the standards of products and services. Building smart cities is the answer that government officials, city planners, and other leaders are seeing as the answer to satisfying the demands of their citizens. Controlling the response of infrastructure through the observation of the nature behavior is a key component of a smart city. Smart technological applications like robotics and artificial intelligence as well as and informed planning ensures the efficient and effective utilization of resources, provides convenience to citizens and helps governing bodies to respond to the changing needs and situations in an agile manner. An enhanced decision-making ability - both regarding short-term day-to-day activities and long-term plans-helps authorities perform their responsibilities like managing their assets, dispensing services, making policy changes, and initiating welfare projects much easier. The proposal of the Mexican government and of citizens, in addition to the scientific and construction societies is adopt systems as the proposed here in order to involve constant engagement through collaborative platforms applications and networks of sensors that enables authorities and citizenship to regard everything they're responsible for.

\section{References}

1. Holzer Thomas L, Johnson Ivan A (1985) Land Subsidence Caused by Ground Water Withdrawal in Urban Areas. GeoJournal 11(3): 245-255.

2. Huanhuan Qin, Charles Andrews B, Fang Tian, Guoliang Cao, Yong Luo et al. (2018) Groundwater-pumping optimization for land-subsidence control in Beijing plain, China. Hydrogeology Journal 26(4): 10611081.

3. Stuart Russell J, Peter Norvig (2009) Artificial Intelligence: A Modern Approach. Pearson Educación SA, Madrid, pp. 1-1240.

4. Graves A, Liwicki M, Fernandez S, Bertolami R, Bunke H et al. (2009) A Novel Connectionist System for Improved Unconstrained Handwriting Recognition. IEEE Transactions on Pattern Analysis and Machine Intelligence 31(5): 855-868.

5. Trejo Medina Lidia Esther, Peña José María Cabrera, Colomo Ricardo José Aguasca, González Blas Galván (2016) Technological, Regulatory Review and Applications of Unmanned Aerial Vehicles in Engineering (Part 1). Dyna Ingeniería e Industria 91(3): 517-521.

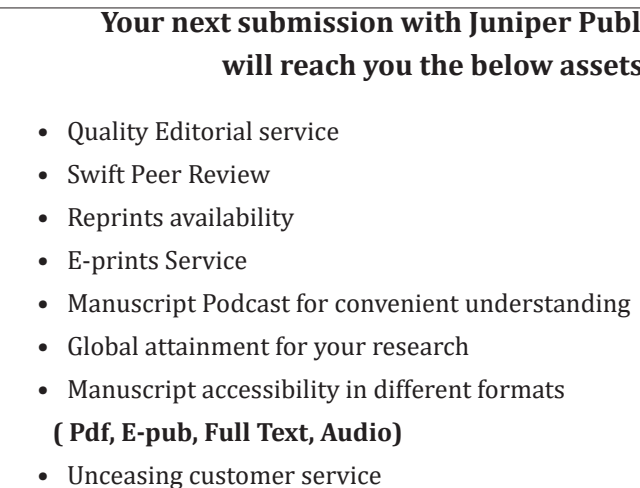

Track the below URL for one-step submission https://juniperpublishers.com/online-submission.php 